\title{
PEMANFAATAN AUGMENTED REALITY SEBAGAI MEDIA PENGENALAN TABOT DI PROVINSI BENGKULU DENGAN METODE SINGLE MARKER BERBASIS ANDROID
}

\author{
Agung Kharismah Hidayah ${ }^{1}$, Anisa Nur Amalah ${ }^{2}$ \\ ${ }^{1,2}$ Program Studi Teknik Informatika, Fakultas Teknik, Universitas Muhammadiyah Bengkulu \\ Jl. Bali Po. Box, 118 Kota Bengkulu 38119 \\ (Telp 0736-22765 Fak. 0736-26161) \\ 1 kharisma@umb.ac.id \\ 2 anisanuramalah@yahoo.co.id
}

\begin{abstract}
Abstrak: Provinsi Bengkulu merupakan salah satu provinsi di Indonesia yang mempunyai potensi pariwisata yang besar dan bervariasi. Budaya yang terdapat di Provinsi Bengkulu dan memiliki jumlah pengunjung yang banyak adalah upacara tradisional Tabot. Demi memperkenalkan Tabot dalam proses promosi sebagai upacara tradisional di Provinsi Bengkulu yang patut dikunjungi dan memiliki nilai sejarah, perlu adanya alternatif media tentang Tabot dalam bentuk 3 dimensi (3D dengan memanfaatkan teknologi augmented reality dengan platform android yang sangat popular pada masa kini. Metode yang digunakan Augmented Reality adalah single marker, dimana satu marker hanya dapat menampilkan satu objek 3D dan tidak dapat membaca lebih dari satu marker. Marker yang digunakan pada aplikasi adalah gambar Tabot dalam bentuk 3 dimensi. Dengan adanya aplikasi ini dapat memperkenalkan perayaan upacara Tabot dan sarana promosi pariwisata di Provinsi Bengkulu kepada masyarakat sebagai pengguna, baik di dalam maupun di luar Provinsi Bengkulu dalam menyukseskan program Wonderfull Bengkulu 2020.
\end{abstract}

Kata Kunci : Augmented Reality, Tabot, Single Marker, Android

Abstract: Bengkulu Province is one of the provinces of Indonesia which has a large and varied tourism potential. One of the cultures in Bengkulu Province that have a large number of visitors is the traditional Tabot ceremony. In order to introduce Tabot particularly in the promotion process as a traditional ceremony of Bengkulu Province is worth a visit and has historical value. It is necessary to have alternative media about Tabot in 3-dimensional form $(3 D$ by utilizing augmented reality technology with the android platform. That is very popular at the present time. The method used in Augmented Reality is a single marker, where one marker can only display one 3D object and cannot read more than one marker. The marker that used in the application is a Tabot image in 3-dimensional form. This application can introduce Tabot ceremony and tourism promotion facilities in Bengkulu Province to the public as users, both inside and outside Bengkulu
Province in the success of the Bengkulu Wonderfull 2020 program.

Keywords: Augmented Reality, Tabot, Single Marker, Android

\section{Pendahuluan}

Pariwisata merupakan sektor yang memiliki peran sentral dalam mewujudkan kesejahteraan masyarakat Indonesia. Indonesia merupakan negara yang sangat kaya dan memiliki daya tarik wisata yang unik, baik dari daya tarik alam, daya tarik budaya dan sejarah yang dapat dikemas dan dikembangkan sebagai tujuan pariwisata dengan mengangkat nilai lokal dan dapat memberikan manfaat bagi masyarakat lokal. 
Provinsi Bengkulu merupakan salah satu provinsi di Indonesia yang mempunyai potensi pariwisata yang besar dan bervariasi. Untuk itu diperlukan Rencana Induk Pengembangan Pariwisata Provinsi Daerah Tingkat I Bengkulu yang merupakan landasan program Pembangunan di Bidang Kepariwisataan dan diharapkan tidak hanya sekedar program saja. Hal ini tidak lepas dari tingginya potensi pariwisata di Bengkulu baik kekayaan alam, bangunan bersejarah maupun budaya. Salah satu budaya yang terdapat di Provinsi Bengkulu dan memiliki jumlah pengunjung yang banyak adalah upacara tradisional Tabot.

Upacara perayaan tradisional tabot Bengkulu telah dilakukan dan diyakini masyarakat Bengkulu sejak abad ke-14 yang merupakan upacara yang berasal dari upacara berkabung kaum syi'ah, yang dibawa oleh para pekerja dari Madras dan Benggali. India di bawah perintah tentara Inggris yang membangun Benteng Marlborough kemudian menikah dengan penduduk setempat. Mereka mengajarkan tradisi kepada anak cucu keturunannya yang disebut suku sipai. Upacara ini telah berlangsung cukup lama dan dipandang sebagai upacara tradisional orang Bengkulu dan menjadi milik mereka baik dari kaum sipai (keluarga tabot) maupun seluruh masyarakat Melayu Bengkulu.

Demi memperkenalkan Tabot dalam proses promosi sebagai upacara tradisional di Provinsi Bengkulu yang patut dikunjungi dan memiliki nilai sejarah, perlu adanya alternatif media tentang Tabot dalam bentuk 3 dimensi (3D dengan memanfaatkan teknologi augmented reality dengan platform android yang sangat popular pada masa kini.

Augmented Reality adalah teknologi yang menggabungkan obyek-obyek maya yang ada dan dihasilkan (generated) oleh komputer dengan benda-benda yang ada di dunia nyata sekitar kita, dan dalam waktu yang nyata [1]. Tidak seperti realitas maya yang sepenuhnya menggantikan kenyataan, Augmented Reality hanya melengkapi kenyataan.

Salah satu metode yang digunakan Augmented Reality adalah single marker, dimana satu marker hanya dapat menampilkan satu objek 3D dan tidak dapat membaca lebih dari satu marker. Cara kerja metode ini adalah image yang telah dibuat kemudian diupload satu per satu ke vuforia untuk dijadikan sebuah marker dan akan mendapatkan penilaian marker mana yang mempunyai kontras tinggi dan pola yang baik sehingga bagus untuk dilakukan tracking.dan kemudian vuforia akan melakukan tracking image terhadap marker tersebut [2].

Kamera yang telah dikalibrasi akan mendeteksi marker yang diberikan, setelah mengenali dan menandai pola marker, kamera akan melakukan perhitungan apakah marker sesuai dengan database yang dimiliki. Jika tidak, maka informasi marker tidak akan diolah, tetapi jika sesuai maka informasi marker akan digunakan untuk me-render dan menampilkan objek 3D atau animasi yang telah dibuat sebelumnya.

\section{LANDASAN TEORI}

\section{A. Tabot}

Menurut sejarahnya Tabot Pertama kali dibawa ke Indonesia oleh orang-orang muslim India. Orang-orang india ini sengaja didatangkan oleh Inggris pada abad ke XVII sebagai serdadu dan pekerja untuk membangun benteng Malborough di Bengkulu. Di samping itu bangsa asing datang ke Bengkulu seperti Portugis, Inggris, Belanda, Tionghoa dan India. 
Bangsa India yang dibawa Inggris berasal dari Benggali dan mereka menganut Agama Islam dari sekte Syi'ah. Selanjutnya budaya Tabot itu dibawa ke daerah-daerah yang disinggahi dari Jazirah Arab seiring dengan masa penyebaran agama Islam ke berbagai penjuru dunia. Budaya Tabot terus masuk ke Punjab (India) lalu dari India budaya Tabot dibawa ke Bengkulu. Sebelum tiba di Bengkulu, orang India tersebut sudah menetap di Aceh, namun karena tidak memperoleh respon yang memadai, mereka meninggalkan Aceh dan mendarat di Bengkulu tahun 756 atau 757 H (1336 M). Jadi yang membawa budaya Tabot di Bengkulu ini adalah orang India dari punjab dan asal muasalnya upacara Tabot ini dari Jazirah Arab.

Upacara Tabot yang ada di Bengkulu mengandung dua aspek ritual dan non-ritual. Aspek ritual hanya boleh dilakukan oleh Keluarga Tabot dan dipimpin oleh dukun Tabot atau orang kepercayaan saja yang memiliki ketentuan khusus dan norma-norma yang harus ditaati. Ritual tabot di Bengkulu dikelompokkan dalam dua jenis. Pertama, Tabot sebagai ritus yang berarti merupakan keseluruhan rangkaian kegiatan ritual yang dilaksanakan mulai malam tanggal 1-10 Muharram. Sebagai ritus, ritual Tabot dipimpin oleh seorang anggota keluarga Tabot yang menguasai secara detail ritual ini dan yang dianggap memiliki kemampuan spiritual untuk melaksanakan ritual tersebut. Kedua, Tabot lebih bersifat fisik. Tabot dalam pengertian ini dipahami sebagai suatu ornamen berbentuk candi atau rumah yang mempunyai satu atau lebih puncak dengan ukuran yang berbeda-beda dibuat dari bahan-bahan tertentu dan dikhususkan untuk ritual Tabot.

\section{B. Tiga Dimensi}

Benda 3 dimensi (3D) adalah sebuah objek/ruang yang memiliki panjang, lebar dan tinggi yang memiliki bentuk. 3D tidak hanya digunakan dalam matematika dan fisika saja melainkan dibidang grafis, seni, animasi, komputer dan lain - lain. Konsep tiga dimensi atau 3D menunjukkan sebuah objek atau ruang memiliki tiga dimensi geometris yang terdiri dari: kedalaman, lebar dan tinggi. Contoh tiga dimensi suatu objek / benda adalah bola, piramida atau benda spasial seperti kotak sepatu. Istilah 3D juga digunakan untuk menunjukkan representasi dalam grafis komputer (digital), dengan cara menghilangkan gambar stereoscopic atau gambar lain dalam pemberian bantuan, dan bahkan efek stereo sederhana, yang secara konstruksi membuat efek 2D [3].

\section{Augmented Reality}

Secara umum, Augmented Reality (AR) adalah suatu teknologi yang menggabungkan benda maya dua dimensi dan ataupun tiga dimensi ke dalam sebuah lingkungan nyata tiga dimensi lalu memproyeksikan benda-benda maya tersebut dalam waktu nyata. Augmented Reality sebagai penggabungan benda-benda nyata dan maya di lingkungan nyata, berjalan secara interaktif dalam waktu nyata, dan terdapat integrasi antar benda dalam tiga dimensi, yaitu benda maya terintegrasi dalam dunia nyata [1].

Selain menambahkan benda maya dalam lingkungan nyata, realitas tertambah juga berpotensi menghilangkan benda-benda yang sudah ada. Menambah sebuah lapisan gambar maya dimungkinkan untuk menghilangkan atau menyembunyikan lingkungan nyata dari pandangan pengguna [4].

\section{Unity $3 D$ Engine}

Unity $3 D$ Engine merupakan suatu software game engine yang terus berkembang saat ini. Penggunaan engine versi free dibatasi dengan beberapa fitur yang dikurangi atau bonus modul 
atau prefab tertentu yang ditiadakan dan hanya tersedia untuk pengguna berbayar. Unity Engine dapat mengolah beberapa data seperti objek tiga dimensi, suara, tekstur, dan lain sebagainya.

Keunggulan dari Unity $3 D$ Engine ini dapat menangani grafik dua dimensi dan tiga dimensi. Namun Unity $3 D$ Engine ini lebih konsentrasi pada pembuatan grafik tiga dimensi. Dari beberapa game engine yang sama-sama menangani grafik tiga dimensi, Unity $3 D$ Engine dapat menangani lebih banyak. Beberapa diantaranya yaitu Windows, MacOS X, iOS, PS3, wii, Xbox 360, dan Android yang lebih banyak daripada game engine lain seperti Source Engine, Game Maker, Unigine, id Tech 3 Engine, id Tech 4 Engine, Blender Game Engine, NeoEngine, Unity, Quake Engine, C4 Engine atau game engine lain. Unity $3 D$ Engine memiliki kerangka kerja (framework) lengkap untuk pengembangan profesional. Sistem inti engine ini menggunakan beberapa pilihan bahasa

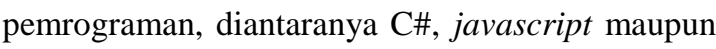
boo [5].

\section{E. Vuforia}

Vuforia adalah Augmented Reality Software Development Kit (SDK) untuk perangkat mobile yang memungkinkan pembuatan aplikasi Augmented Reality. Dulunya dikenal dengan QCAR (Qualcomm Company Augmented Reality). Ini menggunakan teknologi Computer Vision untuk mengenali dan melacak gambar planar (target image) dan objek 3D sederhana, sepertu kotak secara real-time [6].

\section{F. Android}

Android adalah sistem operasi (OS) berbasis linux yang diperuntukan khusus untuk mobile device seperti smartphone atau PC table, persis seperti symbian yang dipergunakan oleh Nokia dan BlackBerry OS, jelasnya seperti microsoft windows yang sangat dikenal baik oleh para pengguna komputer dan laptop, jika kita analogikan, Andoid adalah windows-nya sedangkan smartphone atau hand phone atau tablet adalah unit komputernya [7].

\section{Metode PENELITIAN}

\section{A. Model Pengembangan Sistem}

Model pengembangan sistem yang akan digunakan dalam penelitian ini adalah model Rapid Application Development (RAD). RAD adalah model proses pembangunan perangkat lunak yang incremental. RAD menekankan pada siklus pembangunan yang pendek/ singkat. RAD mengadopsi model waterfall dan pembangunan dalam waktu singkat dicapai dengan menerapkan component based construction.

Sistem dibagi-bagi menjadi beberapa modul dan dikerjakan dalam waktu yang hampir bersamaan dalam batas waktu yang sudah ditentukan.

1. Business modeling berkaitan dengan analisis kebutuhan sistem untuk menampilan 3D dari Tabot.

2. Data modeling berkaitan dengan analisis kebutuhan data. Pengumpulan data diperlukan untuk pengenalan Tabot. Pengumpulan data tersebut akan diperoleh dari dokumentasi, studi pustaka dan observasi. Adapun proses analisis kebutuhan, yang terdiri dari kebutuhan proses, analisis kebutuhan input, analisis kebutuhan output, dan analisis kebutuhan perangkat lunak dan perangkat keras

3. Process modeling dengan menggunakan Unified Modelling Language (UML).

4. Application generation pada aplikasi ini adalah dengan menggambarkan sistem baru yang akan dikembangkan secara logis tanpa mempertimbangkan terlebih dahulu lingkungan sistem. 
5. Testing and turnover dilakukan untuk mendapatkan penilaian langsung terhadap sistem yang dihasilkan.

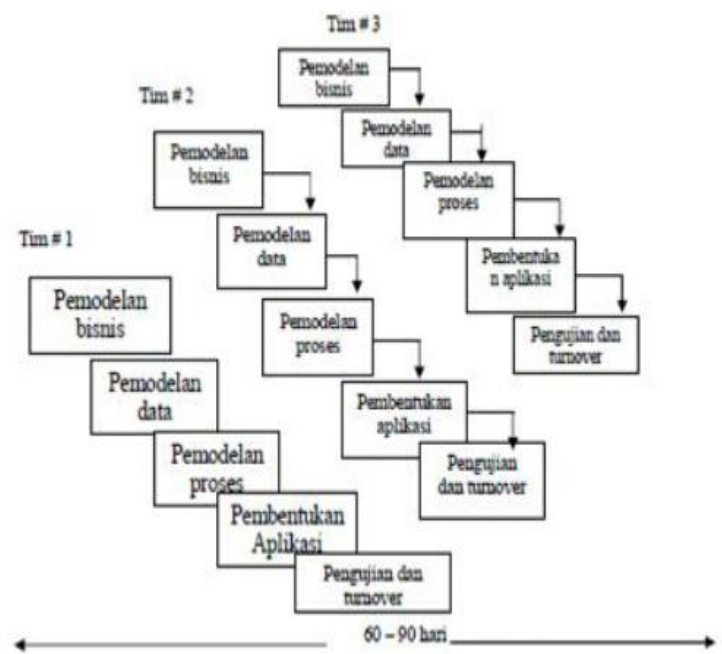

Gambar 1. Model RAD Pembangunan sistem 3D (sumber: Frieyadie. 2014)

\section{B. Metode Pengumpulan Data}

Data yang dibutuhkan untuk membuat media pengenalan Tabot menggunakan teknologi augmented reality berbasis Android, adalah data gambar Tabot dan video festival Tabot

Dalam pengumpulan data untuk memperoleh informasi yang diperlukan, penulis menggunakan beberapa metode yaitu:

\section{Studi Pustaka}

Metode ini dilakukan dengan cara mempelajari buku-buku dan jurnal penelitian yang berhubungan dengan masalah yang dibahas pada objek penelitian, sehingga didapatkan pemahaman yang komprehensif tentang marker, augmented reality, unity $3 D$, sweet home $3 D$, vuforia $S D K$, penerapan augmented reality pada perangkat mobile dengan platform Android dan bahasa pemrograman C\#.

\section{Observasi}

Observasi dilakukan dengan mengamati secara langsung dan melakukan pengambilan foto Tabot dan video festival Tabot di Bengkulu.

C. Perancangan Sistem
Seiring dengan perkembangan teknologi dan semakin banyak pengguna handphone Android maka pengenalan Tabot-pun perlu mengikuti hal tersebut sebagai alternatif lain selain yang telah dilakukan oleh Dinas Pariwisata Provinsi Bengkulu selama ini. Aplikasi pengenalan Tabot akan menggunakan bahasa pemrograman $\mathrm{C \#}$ yang nantinya diharapkan media pengenalan ini bisa memberikan informasi mengenai Tabot dan festival Tabot dalam bentuk 3D dengan menggunakan handphone Android.

\section{Perancangan Aplikasi}

Perancangan aplikasi meliputi proses perancangan navigasi dan perancangan tampilan dari aplikasi. Pada aplikasi pengenalan Tabot menggunakan teknologi augmented reality berbasis Android, terdapat proses-proses yang dapat diimplementasikan, yaitu:

1. Sistem dapat menampilkan Tabot dalam bentuk 3D yang dapat digerakkan secara rotasi sesuai keinginan user dan video playback festival Tabot.

2. Secara umum perangkat lunak ini menggunakan buku sebagai media pendukung penggunaan aplikasi ini. Buku dengan teknologi AR ini secara garis besar berisikan tentang gambar Tabot dan video playback yang berfungsi sebagai penanda (marker). Marker akan menampilkan objek 3 dimensi yang telah dibuat sesuai dengan isi buku.

\section{E. Flowchart}

\section{Flowchart Metode Single Marker}

Aplikasi ini akan menggunakan single marker. Cara kerja metode ini, image yang telah dibuat kemudian di-upload ke vuforia untuk dijadikan sebuah marker dan kemudian vuforia akan melakukan tracking image terhadap marker tersebut. Berikut adalah Gambar flowchart single marker yang digunakan pada penelitian ini. 


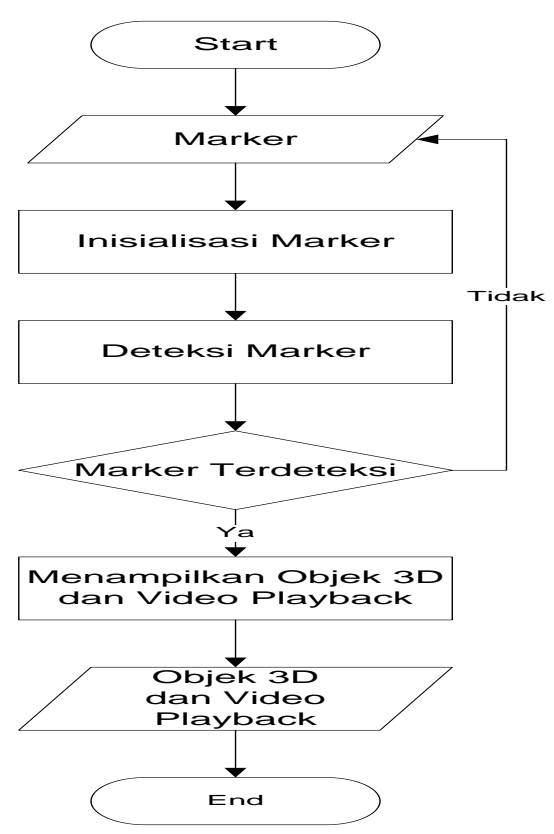

Gambar 2. Flowchart Metode Single Marker

Proses pendeteksian marker dimulai dengan user menunjukkan marker pada kamera. Kemudian kamera akan mendeteksi marker tersebut. Pendeteksian marker tergantung pada beberapa hal, yaitu intensitas cahaya, jarak marker dengan kamera, oklusi (pendeteksia marker terhalang sesuatu) dan resolusi kamera. Jika marker tidak terdeteksi, maka user harus mengatur marker dan menunjukkan kembali pada kamera. Jika marker telah terdeteksi, maka aplikasi akan menampilkan objek 3D yang sesuai dengan marker.

F. Unified Modeling Language (UML)

\section{Use Case Diagram}

Diagram yang bekerja mendeskripsikan tipikal interaksi antara pengguna dengan sebuah sistem melalui sebuah cerita bagaimana sebuah sistem dipakai. Use case diagram terdiri dari sebuah aktor (user) dan interaksi yang dilakukannya (Gambar $3)$.

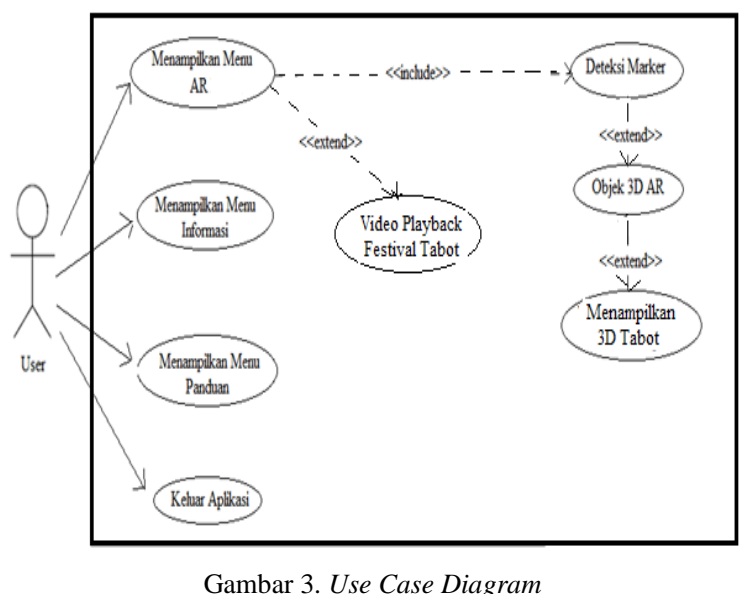

\section{Activity Diagram}

Berdasarkan use case diagram tersebut, maka dapat ditentukan activity diagram dari aplikasi pengenalan Tabot menggunakan teknologi augmented reality berbasis Android seperti terlihat pada Gambar 4.

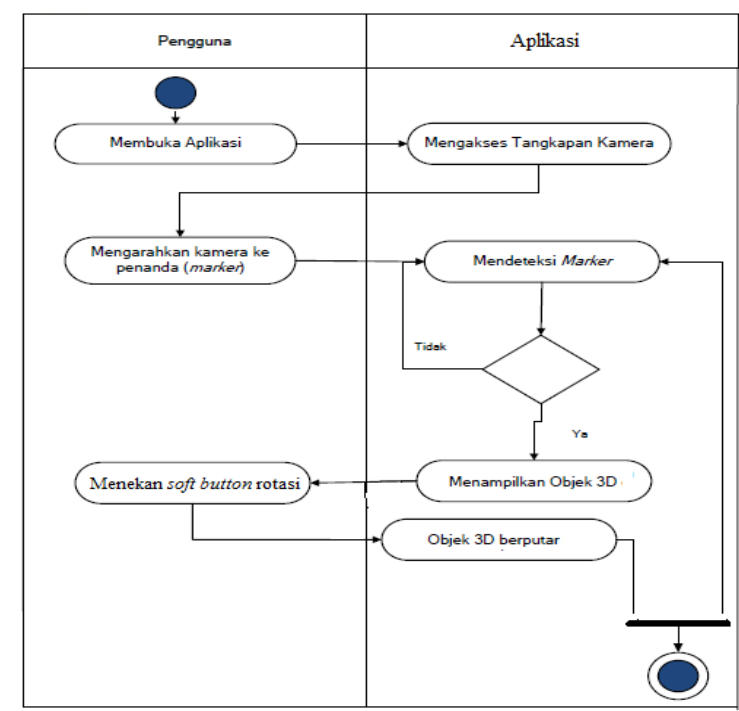

Gambar 4. Activity Diagram Aplikasi

\section{HASIL DAN PEMBAHASAN}

\section{A. Pembuatan Objek $3 D$}

Pembuatan Objek 3D Tabot terdiri dari beberapa tahap, yaitu:

1. Tahap Modelling

Modeling (pembuatan 3 dimensi) dilakukan dengan membuat gambar Tabot dalam bentuk 2 dimensi dan menghasilkan objek 3D dengan tampilan perspective. Pembuatan modeling 
menggunakan ArchiCAD sebagai software untuk membuat atau mendesain model/ miniature Tabot.

Setelah tahap modeling selesai dimana gambar Tabot 2D seleasai dibuat, selanjutnya di preview ke 3D. Modeling Tabot dilakukan dengan membuat gambar setiap tingkatan pada Tabot.

\section{Tahap Texturing}

Setelah proses modeling, selanjutnya proses texturing agar model lebih realistis. Texturing dilakukan pada program $3 D s$ MAX dengan mengubah format file menjadi *.3ds. karena memiliki mapping untuk tekstur suatu objek dan sampel teksturnya diambil dari program ArchiCAD.

\section{Tahap Exporting}

Setelah tahap texturing selesai, model yang selesai dibuat di export kedalam format WRL dan ditampilkan dalam program ARToolkit.

\section{B. Pembuatan Marker}

Fungsi marker sebagai penanda atau medium untuk memunculkan objek 3D pada aplikasi Augmented Reality. Marker dibuat dalam program Photoshop dan disisipkan pada desain layout. Setelah pembuatan marker ini selesai, agar marker dapat dikenali oleh aplikasi unity 3D-nya, langkah selanjutnya adalah unggah marker yang sudah dibuat pada vuforia. Gambar 5. adalah marker Tabot yang terdiri dari Tabot dan video perayaan Tabot di Provinsi Bengkulu.
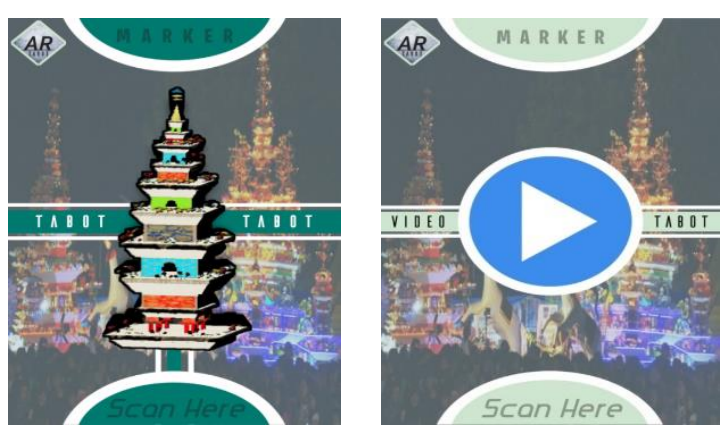

Gambar 5. Marker Tabot dan Video Perayaan Tabot Provinsi Bengkulu

\section{Implementasi Aplikasi ARToolkit}

Objek 3D Tabot yang didesain menggunakan software modeling ArchiCAD dan 3Ds Max diexport dengan format * .WRL. Setelah di-export dengan format *.WRL, file model tersebut dimasukkan ke dalam folder aplikasi ARToolkit/bin/Wrl. Dan selanjutnya membuat file tempat menyimpan database objek 3D yang berbentuk Wrl. Pada folder aplikasi ARToolkit/bin/Wrl, pilih file berekstensi *.dat dan copy-paste file tersebut tetap didalam folder $\mathrm{Wrl}$ dan mengganti nama file-nya sesuai nama file objek.

\section{Identifikasi Marker Melalui Kamera}

Marker yang telah dirancang belum bisa dikenali aplikasi ARtoolkit, agar dapat dikenali marker yang telah dibuat perlu dideteksi atau dikenali kamera dengan membuka file marker pada folder aplikasi ARToolkit/Bin. Setelah file 3D objek telah disisipkan pada folder aplikasi ARToolkit dan marker telah dikenali oleh kamera, selanjutnya me-render objek 3D.

\section{E. Rendering Objek $3 D$}

Setelah file $3 D$ objek telah disisipkan pada folder aplikasi ARToolkit dan marker telah dikenali oleh kamera, selanjutnya merender objek 3D. dengan menjalankan simplevrml.exe pada folder ARToolkit/Bin. Objek 3D model setiap gedung akan direndering oleh simplevrml.exe dan muncul layar kamera. Arahkan ke marker yang telah disisipi pada peta yang sebelumnya sudah dibuat pada layar kamera.

\section{F. Uji Coba Aplikasi AR ke Handphone}

Uji coba aplikasi dilakukan setelah menghasilkan *.apk, selanjutnya copy dan install folder *.apk pada handphone. Setelah berhasil menginstallkan folder *.apk maka aplikasi dapat dijalankan. 
Jurnal Pseudocode, Volume VII Nomor 1, Februari 2020, ISSN 2355-5920, e-ISSN 2655-1845 www.ejournal.unib.ac.id/index.php/pseudocode

\section{Menu Utama Aplikasi AR}

Menu Utama Aplikasi AR merupakan tampilan menu awal dari aplikasi AR terdiri dari empat pilihan menu, yaitu AR, Informasi, Panduan dan Keluar. Gambar 6. adalah tampilan awal saat aplikasi AR dijalankan dan Gambar 7. adalah tampilan Menu Utama Aplikasi AR.

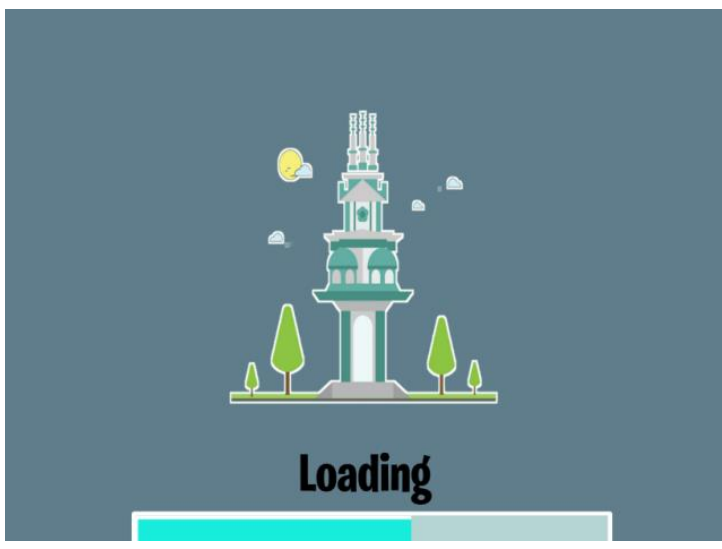

Gambar 6. Tampilan Splash Screen Aplikasi

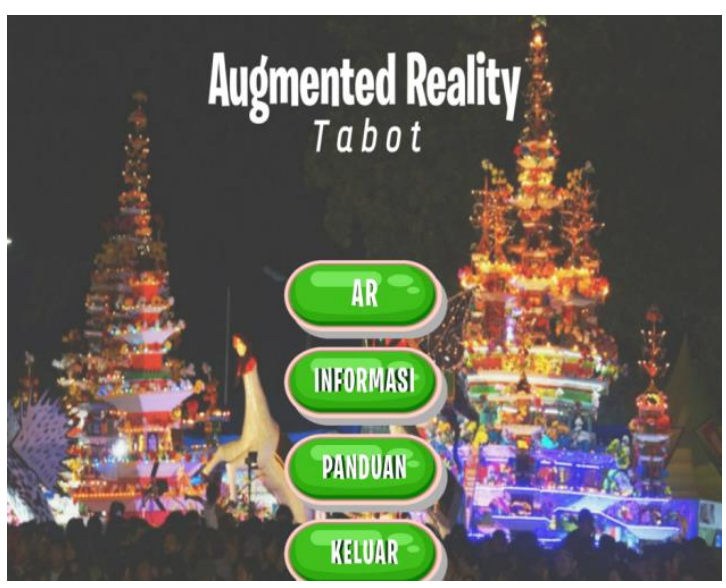

Gambar 7. Tampilan Menu Awal Aplikasi

\section{Menu AR}

Menu AR digunakan untuk melihat gambar 3D dari Tabot dan video Perayaan Tabot di Provinsi Bengkulu. Jika Menu AR dipilih, maka handphone akan langsung terhubung dengan kamera dan proses deteksi marker dapat dilakukan. Gambar 8. adalah gambar 3D dari Tabot yang terdapat fasilitas rotasi dan 4.5 merupakan video perayaan Tabot.

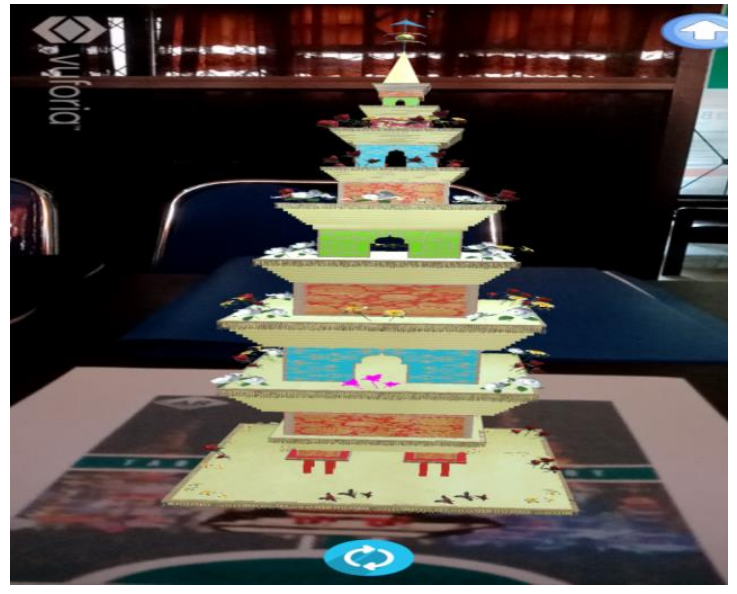

Gambar 8. 3D Tabot

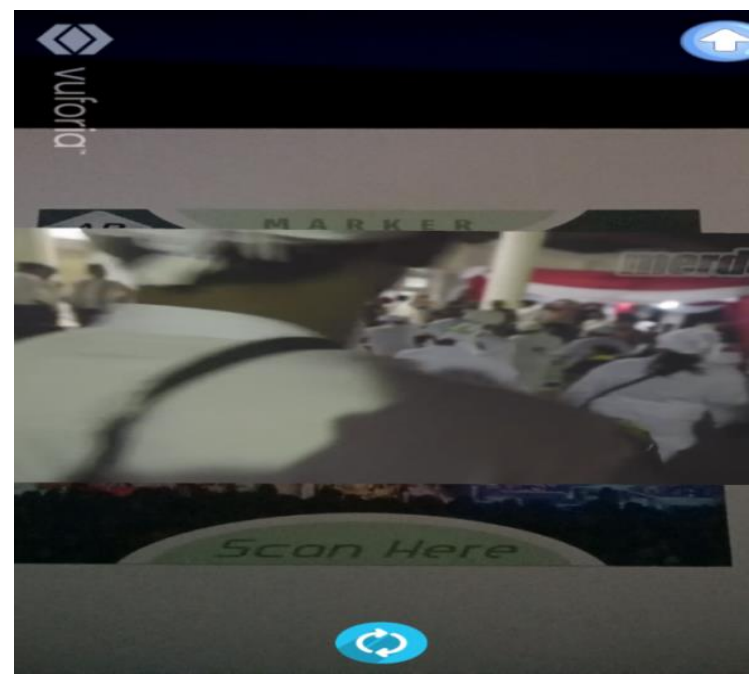

Gambar 9. Video Parayaan Tabot

3. Menu Informasi

Menu Informasi merupakan menu yang digunakan untuk mengetahui informasi tentang Tabot (Gambar 10).

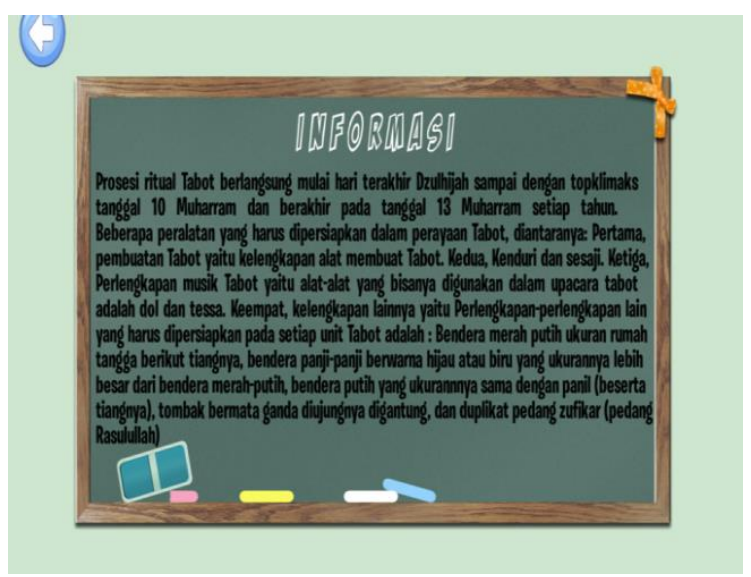

Gambar 10. Menu Informasi Tabot 


\section{Menu Panduan}

Menu Panduan merupakan menu yang digunakan untuk mengetahui tata cara menggunakan aplikasi AR (Gambar 11).

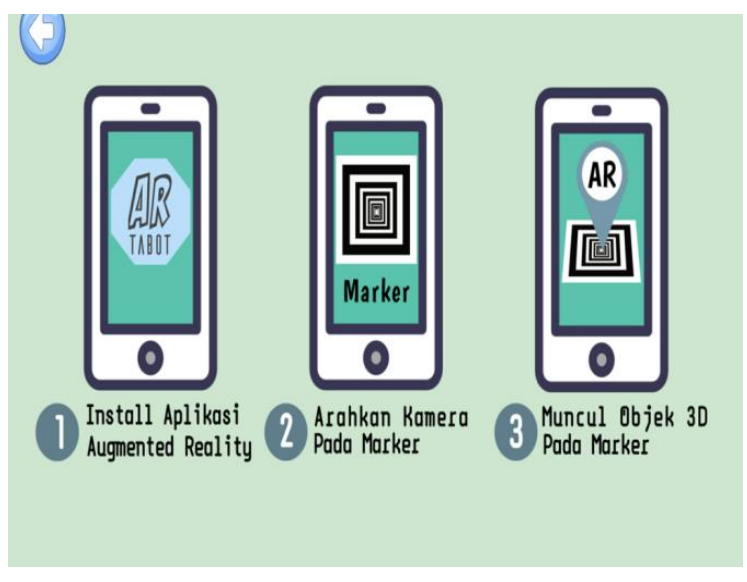

Gambar 11. Menu Panduan Aplikasi

\section{Menu Keluar}

Menu Keluar digunakan apabila pengguna ingin keluar dari aplikasi (Gambar 12).

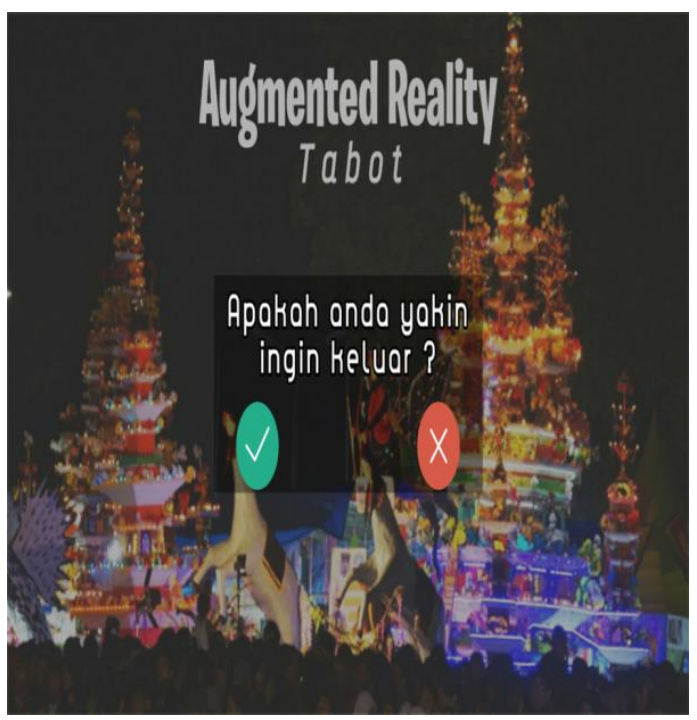

Gambar 12. Menu Keluar Aplikasi

\section{G. Pengujian}

Pengujian dilakukan untuk melihat apakah aplikasi AR yang telah dibuat berjalan sesuai dengan yang diharapkan. Pengujian terdiri dari dua jenis uji yaitu pengujian terhadap marker dan pengujian terhadap fungsi yang terdapat pada aplikasi. Untuk pengujian marker dapat dilihat pada Tabel 1. sampai dengan Tabel 3. Pengujian fungsi menggunakan metode black box dapat dilihat pada Tabel 4 .

Tabel 1. Pengujian Jarak Kamera dengan Marker

\begin{tabular}{|c|c|}
\hline Jarak $(\mathbf{c m})$ & Tingkat Keberhasilan \\
\hline $5 \mathrm{~cm}$ & Berhasil \\
\hline $10 \mathrm{~cm}$ & Berhasil \\
\hline $30 \mathrm{~cm}$ & Berhasil \\
\hline $40 \mathrm{~cm}$ & Berhasil \\
\hline $50 \mathrm{~cm}$ & Tidak Berhasil \\
\hline $100 \mathrm{~cm}$ & Tidak Berhasil \\
\hline
\end{tabular}

Pada pengujian jarak Kamera dengan Marker diatas dapat dilihat bahwa Kamera dapat mendeteksi marker pada jarak $5-40 \mathrm{~cm}$. Sedangkan pada jarak lebih jauh dari $40 \mathrm{~cm}$ kamera tidak dapat mendeteksi marker.

Tabel 2. Pengujian Pencahayaan

\begin{tabular}{|l|l|}
\hline \multicolumn{1}{|c|}{ Pencahayaan } & Tingkat Keberhasilan \\
\hline Siang hari (matahari) & Berhasil \\
\hline Malam hari (lampu) & Berhasil \\
\hline $\begin{array}{l}\text { Malam hari (lampu dengan } \\
\text { penghalang) }\end{array}$ & Berhasil \\
\hline Malam hari (tanpa lampu) & Tidak Berhasil \\
\hline
\end{tabular}

Berdasarkan hasil pengujian pencahayaan pada

Tabel 2. didapatkan bahwa kamera dapat mendeteksi marker apabila terdapat pencahayaan yang cukup seperti pada siang hari atau malam hari dengan bantuan lampu. Apabila dilakukan malam hari tanpa bantuan lampu dan pencahayaan yang cukup maka kamera tidak dapat mendeteksi marker.

Tabel 3. Pengujian Sudut Kemiringan Kamera dengan Marker

\begin{tabular}{|c|c|}
\hline Sudut Kemiring & Tingkat Keberhasilar \\
\hline $0^{0}$ & Berhasil \\
\hline $45^{\circ}$ & Berhasil \\
\hline $90^{\circ}$ & Tidak Berhasil \\
\hline
\end{tabular}

Berdasarkan hasil pengujian pada tabel 3 . diketahui bahwa kamera dapat mendeteksi marker pada sudut kemiringan yang pas yakni pada sudut kemiringan $0^{\circ}$ dan $45^{\circ}$.

Tabel 4. Pengujian Black Box

\begin{tabular}{|l|l|}
\hline \multicolumn{1}{|c|}{ Menu } & Tingkat Keberhasilan \\
\hline Menu AR & Berhasil \\
\hline Menu Informasi & Berhasil \\
\hline Menu Panduan & Berhasil \\
\hline Menu Keluar & Berhasil \\
\hline Kamera & Berhasil \\
\hline Tombol Rotasi & Berhasil \\
\hline Tombol Home & Berhasil \\
\hline Tombol Back & Berhasil \\
\hline
\end{tabular}


Berdasarkan hasil pengujian black box diketahui bahwa semua menu dan tombol serta kamera dapat bekerja dengan baik.

Dari rangkaian pengujian yang telah dilakukan dapat disimpulkan bahwa aplikasi ini telah berfungsi dengan baik dibuktikan dengan semua menu dan tombol yang ada berhasil berfungsi sebagaimana mestinya. Pada saat proses deteksi marker dipengaruhi oleh beberapa hal yaitu jarak yang pas, pencahayaan yang cukup, dan sudut kemiringan yang tepat.

\section{KESIMPULAN DAN SARAN}

\section{A. Kesimpulan}

Dari penelitian yang telah dilakukan, didapatkan beberapa kesimpulan antara lain:

1. Objek tiga dimensi dapat divisualisasikan dalam perangkat handphone saat kamera mendeteksi kertas gambar yang telah dijadikan sebagai marker.

2. Jarak pada saat proses tracking ke marker sangat mempengaruhi muncul tidaknya sebuah objek 3D. Jarak yang diperlukan agar marker terdeteksi oleh sistem adalah kurang dari 50 $\mathrm{cm}$.

3. Semakin bagus intensitas cahaya yang didapatkan maka sistem akan semakin cepat dalam mengenali marker dan sebaliknya Ketika tidak terdapat cahaya maka sistem tidak dapat mendeteksi marker.

\section{B. Saran}

Saran yang dapat diberikan untuk penelitian yang memanfatkan teknologi augmented reality lebih lanjut adalah:

1. Menggunakan metode lain selain single marker seperti markerless (tanpa marker).

2. Penambahan pergerakkan objek menggunakan touch.

\section{REFERENSI}

[1] Azuma RT. 1997. A survey of Augmented Reality. In Presence: Teleoperators and Virtual Environment 6: 355-385.

[2] Desy. 2017. MonsterAR: Mengenal Jenis-Jenis dari Teknologi Augmented Reality?.https://monsterar.net/2017/08/08/mengenaljenis-augmented-reality/. Diakses tanggal 8 Juli 2019

[3] Ardhianto E, Hadikurniawati W, Winarno E. 2012. Augmented Reality Objek 3 Dimensi dengan Perangkat ARToolKit dan Blender. Jurnal Teknologi Informasi Dinamik Volume 17 No 2: 107-117.

[4] Andriyadi A. 2011. Augmented Reality With ARToolkit Reality Leaves a lot to Imagine. Lampung. Augmented Reality Team.

[5] Remondino AM. 2012. A review of Reality-Based 3D Model Generation, Segmentation and Web-Bassed Visualization Methods.

[6] Rentor MF. 2013. Membuat Aplikasi Augmented Reality Menggunakan Vuforia SDK dan Unity. Yogyakarta. Universitas Atma Jaya Yogyakarta.

[7] Furht B. 2011. Handbook of Augmented Reality. Florida: Department of Computer and Electrical Engineering and Computer Science.

[8] Frieyadie. 2014. Penggunaan model RAD untuk pembangunan sistem informasi penjualan tiket bus online 